\title{
LA MEDIACIÓN ADMINISTRATIVA
}

\author{
Autor: Casiano Rojas Pozo ${ }^{1}$ \\ Magistrado
}

\section{Resumen}

Este trabajo tiene por objetivo mostrar cuál es la situación actual de la mediación administrativa, comprendiendo en esta expresión tanto lo que se puede llevar a cabo en sede de expediente administrativo como la mediación intrajudicial cuando el conflicto está judicializado. Muestra que la primera está inédita. Y respecto de la segunda se comprueba que el CGPJ ha diseñado una mediación a través de mediadores privados completamente ineficaz en esta jurisdicción. Pretendemos demostrar que la mediación intrajudicial debe canalizarse potenciando la transacción judicial del artículo 77 LJCA y esbozamos muy someramente la forma que debería implementarse la mediación en sede de expediente administrativo mediante la creación de entes administrativos de mediación.

Palabras clave: mediación; transacción; entes administrativos de mediación; mediadores privados.

\section{Administrative mediation}

\footnotetext{
${ }^{1}$ C.rojas@poderjudicial.es
} 


\begin{abstract}
This paper aims to show what the current situation of administrative mediation, understanding in this expression both what can be done in headquarters administrative record as intrajudicial mediation when the conflict is judicialized. Sign that the former is unprecedented. And regarding the second is found that the CGPJ has designed mediation through private mediators completely ineffective in this jurisdiction. We intend to demonstrate that mediation should be channeled enhancing intrajudicial court settlement Article 77 LJCA and outline very briefly the way it should be implemented mediation headquarters administrative record by creating mediation administrative bodies.
\end{abstract}

Key words: mediation; transaction; mediation administrative bodies; private mediators.

\title{
1. LA MEDIACIÓN EN SEDE DE EXPEDIENTE ADMINISTRATIVO
}

\subsection{La realidad actual}

Por Orden Ministerial de 11 de julio de 2012 se crea una Sección Especial, en el seno de la Comisión General de Codificación, para la reforma de la Ley 29/1998, de 13 de julio, Reguladora de la Jurisdicción Contencioso-Administrativa -BOE de 14 de julio de 1998- (en adelante LJCA).

Los trabajos de esta Comisión se han concretado en dos documentos denominados "Informe explicativo y propuesta de anteproyecto de ley de eficiencia de la Jurisdicción Contencioso-Administrativa"” y "Propuesta de anteproyecto de Ley de eficiencia de la Jurisdicción Contencioso-administrativo"”.

Del primero de ellos puede deducirse cuál es el estado de la mediación administrativa actualmente en nuestro País y cuáles son las perspectivas de futuro. Y es que, además de abordar los concretos contenidos para las que fue creada, la Sección aborda, siquiera muy tangencialmente, la institución de la mediación judicial y la posibilidad de potenciar la transacción judicial residenciada en el artí-

\footnotetext{
${ }^{2}$ Comisión General de Codificación, Informe explicativo y propuesta de anteproyecto de ley de eficiencia de la Jurisdicción Contencioso-Administrativa, Ministerio de Justicia, Madrid, 2013.

${ }^{3}$ Comisión General de Codificación, Propuesta de anteproyecto de Ley de eficiencia de la Jurisdicción Contencioso-administrativo, Ministerio de Justicia, Madrid, 2013.
} 
culo 77 LJCA. En efecto, textualmente se dice 4 que: "Otras veces eran cuestiones de especial complejidad -tanto técnica como de regulación normativa- que exigían un tratamiento singular no abordable con suficiencia en el limitado mandato de la Sección. En este sentido, la Sección ha debatido propuestas diversas sobre la posibilidad de fomentar la mediación (tanto administrativa como judicial) o de potenciar la transacción contenciosa (respecto de la actual regulación del art. 77 LJCA). Pero la propia Sección ha considerado que esas posibles innovaciones normativas presentan numerosas implicaciones transversales. Así, por ejemplo, la introducción de la mediación administrativa tendría que ser armonizada con los actuales "defensores" administrativos, sectoriales o generales; también, la potenciación de la transacción judicial implicaría, además de fomentar una mayor cultura y sensibilidad por estos instrumentos, un consenso muy amplio y su plasmación en reformas organizativas y procedimentales. En estos y otros temas, la prudencia -y una vez más la acotación funcional y temporal de la Sección Especial- han aconsejado que los debates de la Sección no se trasladaran a propuestas normativas concretas. Con todo, si bien el presente informe final no contiene propuestas normativas específicas sobre todas estas cuestiones, sí que da cuenta de los argumentos, debates y propuestas manejados por la Sección”.

Y a continuación se introduce en la cuestión sobre la base de considerar que faltan instrumentos jurídicos para la evitación de litigios contenciosos": "En España se puede hablar de un insuficiente sistema de evitación de los litigios contencioso-administrativos. Esto se refiere fundamentalmente a tres realidades: la ineficacia relativa de los recursos administrativos; la falta de instrumentos procedimentales para evitar que una Administración dicte resoluciones idénticas a otras ya impugnadas y que se encuentran pendientes de resolución judicial firme; y, por último, la baja implantación relativa de la mediación administrativa".

Respecto de la primera realidad, asume que "Los recursos administrativos generales (alzada y reposición) no sirven con eficacia para evitar litigios contencioso-administrativos". Tres razones pueden explicar esta conclusión a juicio de la Sección Especial:

a) La primera es que una parte importante de los recursos administrativos se resuelve presuntamente, esto es, por silencio administrativo negativo.

b) La segunda razón es la escasa operatividad estructural de un recurso, como el de alzada, que normalmente relaciona a cargos superiores de cada Administración. Hay que tener en cuenta que la tradición administrativa española es de alta concentración de las funciones resolutivas en niveles altos

\footnotetext{
${ }^{4}$ Informe Explicativo y Propuesta de Anteproyecto de Ley de Eficiencia en la Jurisdicción contenciosoadministrativa, cit., p. 12.

${ }^{5}$ Ídem, pp. 24 y siguientes.
} 


\section{Casiano Rojas Pozo}

de la Administración. Esto es, en los Secretarios de Estado, Subsecretarios y Directores Generales (en la Administración General del Estado); en los Consejeros, Secretarios Generales y Directores Generales (en las Comunidades Autónomas); en el Pleno, Junta de Gobierno Local y Alcalde (o concejales por delegación), en los Ayuntamientos; o, por poner un ejemplo de Administración institucional, en el Rector y Consejo de Gobierno de las Universidades. Incluso las normas de desconcentración, donde existen, sólo trasladan competencias entre órganos superiores de la Administración. No hay tradición en España de que al menos las resoluciones regladas se dicten por órganos directivos o simplemente técnicos de la Administración. Esta situación estructural produce, en lo que aquí importa, dos efectos relevantes. Uno es el alto número de resoluciones administrativas que no son recurribles en alzada (porque agotan la vía administrativa). El ejemplo paradigmático es la Administración local. El segundo efecto anunciado es el bajo número relativo de recursos administrativos estimados.

c) Por último, en lo que hace al recurso de reposición, su propia configuración normativa (resuelve el mismo cargo que ha decidido: art. 116 LRJ-PAC) augura un nivel bajo de estimación.

Respecto de la tercera realidad se dice que "c) Por último, en la actualidad la mediación administrativa tampoco es, en términos relativos, un instrumento eficaz para la evitación de litigios. La mediación administrativa se manifiesta, en España, mediante diferentes ombúdsmanes (defensores) sectoriales o generales (defensores del pueblo, defensores del paciente, defensores del contribuyente, defensores del universitario, etc.). No hay duda de que, donde existen, estos órganos evitan un cierto número de litigios. Pero su implantación, medios y posición procedimental no permiten, actualmente, mejores resultados. Es cierto que en otros países de nuestro entorno los datos globales de mediación no son más apreciables. Pero también es cierto que en los últimos años se han acelerado las reformas normativas y organizativas para mejorar la funcionalidad de la mediación administrativa, fundamentalmente en el Reino Unido".

Y a la vista de esta realidad realiza sus propuestas normativas para conseguir que los conflictos jurídico-administrativos se resuelvan anticipadamente, sin necesidad de acudir al proceso contencioso-administrativo, que, en cuanto ahora interesan, es el refuerzo de los controles administrativos de legalidad. Y respecto de la mediación se limita a decir que "La Sección también ha tomado en consideración las posibilidades de mejorar la mediación administrativa, como técnica alternativa al litigio. Sin embargo, la misma Sección finalmente ha optado por dejar estas cuestiones al margen de sus propuestas".

El refuerzo de los controles administrativos de legalidad pasa por la creación de algunos órganos independientes -siempre de carácter sectorial- para la re- 
solución de controversias jurídicas, aprovechando la experiencia de positiva de algunos órganos administrativos de control de legalidad ya existentes, como los Tribunales Económico Administrativos, el Consell Tributari de Barcelona o los Tribunales Administrativos Especiales de Recursos Contractuales. Se propone así crear Comisiones Administrativas Independientes para la resolución de los recursos administrativos de alzada y reposición, mediante la introducción de un nuevo apartado 5 en el artículo 107 de la Ley 30/92. No se trata de una sustitución absoluta de los recursos de alzada y reposición por otro medio de impugnación, que es lo que prevé actualmente el art. 107.2 LRJ-PAC, sino de algo más sencillo: la sustitución del órgano que resuelve, que pasa a ser una comisión independiente.

En concreto se proponen las Comisiones Independientes de Empleo Público (mediante la introducción de un nuevo "Título IX. De los recursos de empleo público” en la Ley 7/2007, de 12 de abril, del Estatuto Básico del Empleado Público), la Comisión Central de Extranjería (mediante la introducción de un nuevo “Título V. La Administración de extranjería” en la Ley Orgánica 4/2000, de 11 de enero, sobre Derechos y Libertades de los Extranjeros en España y su Integración Social), la Comisión Central de Tráfico (mediante la introducción de un nuevo apartado 3 en el artículo 6 del Real Decreto Legislativo 339/1990, de 2 de marzo, por el que se aprueba el Texto Articulado de la Ley sobre Tráfico, Circulación de Vehículos a Motor y Seguridad Vial).

Sin embargo, la, ahora en vacatio, Ley 39/2015, de 1 de octubre, del Procedimiento Administrativo Común de las Administraciones Públicas (BOE núm. 236, de 25 de octubre, pp. 89343 a 89410), no ha seguido la propuesta de la Sección Especial en la Comisión de Codificación y no ha introducido las Comisiones Administrativas Independientes.

Posteriormente, como meras propuestas de futuras reformas legislativas, la Sección "toma en consideración" la posibilidad de regular expresamente (en la propia LJCA o en una Ley específica) la mediación judicial, esbozando muy someramente cuáles sería sus líneas básicas en función de "experiencias foráneas" de nuestro entorno (Francia, Alemania y Reino Unido). A su juicio de esta experiencia resulta que:

- La mediación puede ser tanto mediante un juez (distinto del que tramita la causa) como con otro sujeto. La mediación judicial parece dar buenos resultados (se beneficia de la imagen de independencia del juez).

- La mediación judicial sólo es idónea para un pequeño número de casos: aquellos que se refieren a cantidades pecuniarias y donde el Derecho aplicable es sencillo (fundamentalmente: responsabilidad patrimonial pública).

- En general, la mediación depende de la existencia de incentivos para su uso por las partes y el juez. En el caso de Inglaterra se va consolidando un criterio judicial que lleva a la sanción (costas judiciales) a aquella parte que no atiende con diligencia a una posible mediación propuesta por la otra parte. 


\section{Casiano Rojas Pozo}

De ello puede deducirse que en ningún momento se ha planteado la Sección Especial la posibilidad de esbozar lo que sería la mediación administrativa (esto es, la llevada a cabo en sede de expediente administrativo), cuya única referencia en los documentos mencionados se encuentra en los "diferentes ombúdsmanes (defensores) sectoriales o generales (defensores del pueblo, defensores del paciente, defensores del contribuyente, defensores del universitario)", puesto que cuando habla de mediación se refiere a la judicial, esto es, la que puede canalizarse una vez el conflicto está judicializado.

En resumen, parece que el criterio que se impone es de establecer "Tribunales" dentro del seno de la propia organización administrativa, con la finalidad de establecer "controles administrativos de legalidad" (no otra cosa son las Comisiones Administrativas Independientes), en vez de crear órganos para llevar a cabo una labor de mediación en el seno de esa misma organización, entendido el término "mediación", en el único que, a nuestro juicio, es posible, desde el punto de vista de la eficacia en la resolución de conflictos en el ámbito del Derecho Administrativo, que no es otro que un análisis de oportunidad y conveniencia, y que conduce inexorablemente a una solución transaccional, cuando ese análisis lo posibilita.

Cabe preguntarse la razón por la que nuestros Legisladores, y también los trabajos preparatorios de los expertos nombrados al efecto, buscan la solución a los conflictos mediante la fórmula de creación de órganos caracterizados como tribunales y no a través de entes mediadores. Seguramente la respuesta la encontramos en la falta de conciencia mediadora en nuestra sociedad. A este respecto es completamente inaudito que nuestros hijos acaben su formación escolar obligatoria (la más importante sin duda en la conformación de su personalidad) conociendo que hay exclusivamente dos formas de resolver un problema: por la vía de la fuerza física o por la vía de la denuncia ante los Tribunales de Justicia. Mientras que no se enseñe en la escuela que existe la tercera vía que supone la mediación difícilmente vamos a conseguir verdaderos progresos en este ámbito.

Y al hilo de ello, sería muy interesante que todos los colegios e institutos de este país tuvieran la oportunidad de comparar lo que sería la solución de un conflicto determinado por vía de la mediación y por la vía de los Tribunales de Justicia. La propuesta sería combinar el programa "Educando en Justicia" creado por el CGPJ, con otro programa que denominaríamos "Educando en mediación".

\subsection{Nuestro planteamiento}

En efecto, no se trata de crear órganos de supervisión de legalidad (meros sucedáneos de los recursos administrativos) que poco, o muy poco, solucionan, sino de buscar soluciones transadas, mediante la concesión de recíprocas concesiones entre Administración y ciudadano/a, cuando se constate, en el seno de una negociación auspiciada bien por entes independientes, que estamos ante un conflicto 
dudoso, en términos de solución definitiva en sede jurisdiccional, precisamente para evitarla.

Y para alcanzar esa solución transada, es preciso que el juicio de probabilidad y conveniencia que realicen las dos partes, permita un punto de encuentro que evite el conflicto. Nuestro planteamiento lo explicamos con más detalle seguidamente cuando analizamos la situación de la mediación intrajudicial.

Ahora es suficiente con esbozar lo que sería a nuestro juicio un instrumento eficaz para que la mediación administrativa cumpla la función que le es propia, esto es, evitar la judicialización del conflicto.

Las notas fundamentales de su régimen jurídico sería el siguiente:

a) Debe llevarse a cabo en el seno de un ente público, creado expresamente al efecto o aprovechando la estructura de otros existentes (como pueden ser el defensor del pueblo a nivel estatal o los defensores del pueblo a nivel autonómico). O instituciones semejantes, como los Consejos Consultivos autonómicos o similares (como la recién creada en Extremadura Comisión Jurídica de Extremadura por la Ley 19/2015, de 23 de diciembre, por la que se deroga la Ley 16/2001, de 14 de diciembre, reguladora del Consejo Consultivo de Extremadura, DOE 29/12).

b) Es esencial que los miembros de este ente sean nombrados entre profesionales expertos en las distintas ramas del Derecho Administrativo, que gocen de un merecido y reconocido prestigio en su ámbito de actuación propio. Nosotros proponemos que se cree un ente administrativo mediador en cada Comunidad Autónoma, con competencia para mediar, a fin de transar el conflicto, entre la Administración Pública que haya dictado el acto, cualquiera que sea (utilizando las fórmulas de cooperación entre ellas que sean precisas) y los ciudadanos/as con residencia en ellas. Su estatuto jurídico será de total autonomía y serán nombrados por mayoría absoluta de las respectivas Asambleas Legislativas. La ley que lo cree determinará las materias susceptibles de transacción.

c) El ciudadano/a que considere que el acto administrativo vulnera la legalidad tiene que tener la facultad de solicitar someter el asunto al ente administrativo mediador (en adelante mediador) de su Comunidad Autónoma, en cuyo caso no será necesario que agote la vía administrativa mediante la interposición de los recursos (alzada o reposición, según corresponda) para poder acudir a la vía jurisdiccional. La Administración estará obligada a comparecer al proceso mediador instado por el ciudadano/a, siempre que el mediador haya tomado la decisión de admitir a trámite la solicitud de mediación por estar ante una materia transable y que presenta margen para la negociación transadora. En otro caso, se entenderá agotada la vía administrativa y le quedará expedita la vía jurisdicción, con la certificación emitida por el mediador. 


\section{Casiano Rojas Pozo}

d) Acordada por el mediador la admisión a trámite del proceso mediador solicitado por el ciudadano/a, se llevará a cabo mediante comparecencia ante el mediador, a la que acudirán el ciudadano/a personalmente, acompañado por su asistencia letrada, si lo considera necesario, y en su caso profesional técnico que le interese, y el letrado de la respectiva Administración Pública que haya dictado el acto cuestionado (Abogado del Estado, Letrados de la respectiva Comunidad Autónoma, Letrado de las Administraciones Locales etc). En ese acto las partes intentarán alcanzar el acuerdo. En caso de no ser posible se emitirá certificación por el mediador quedando expedita la vía judicial en el plazo legal. En caso de afirmativo se redactará en el acto propuesta de acuerdo de transacción, que deberá ser autorizado por el órgano de la Administración que corresponda (nosotros proponemos que se residencie en los respectivos responsables de los Servicios Jurídicos de cada Administración Pública) en el plazo máximo de 15 días. En caso de no existir respuesta en ese plazo se entenderá que no se ha concedido la autorización y quedará expedita la vía judicial para el ciudadano/a.

e) El ciudadano/a que haya acudido a la vía de la mediación no tendrá que abonar las costas del juicio contencioso-administrativo, excepto en el supuesto de que se entienda que el recurso es temerario.

f) Ni que decir tiene que todo el proceso de mediación es gratuito.

\section{LA MEDIACIÓN INTRAJUDICIAL}

\subsection{Situación actual}

Actualmente la mediación intrajudicial en la jurisdicción contencioso-administrativa se residencia, exclusivamente, en el artículo 77 LJCA. Y a nuestro juicio debe seguir así, pues defendemos que es la única fórmula realmente eficaz.

Sobre ella la Sección Especial señala que ${ }^{6}$ se "ha debatido la posibilidad de promocionar y completar el sentido procesal del actual trámite de conciliación o transacción regulado en el art. 77 LJCA. En este sentido, la Sección ha conocido y debatido sobre las experiencias de transacción en otros Estados de nuestro entorno. Se puede destacar, por ejemplo, el impulso dado a la transacción en Francia, en el marco de la promoción de modos alternativos de resolver los conflictos y buscando la culminación de vías amistosas o de conciliación para solucionar litigios con la Administración. Impulso del que es una reciente muestra la Circular del Primer Ministro de 6 de abril de 2011. En el caso de España, la Sección ha debatido, sin llegar a conclusiones definitivas, la posibilidad de potenciar la comparecencia que

\footnotetext{
${ }^{6}$ Informe Explicativo..., cit., pp. 111 y ss.
} 
el art. 77 LJCA regula con carácter potestativo. Esta comparecencia -a celebrar después de formulada la demanda y contestación- podría establecerse con carácter obligatorio y tendría por objeto centrar y acotar el debate, facilitar el espacio procesal para proponer e intentar una mediación intrajudicial, proponer la prueba a practicar y declarar su pertinencia, así como plantear el recurso contra la admisión o inadmisión de los medios probatorios propuestos. La celebración de la comparecencia del art. 77 LJCA podría favorecer un conocimiento y estudio anticipados del asunto por parte de los magistrados, lo que a su vez podría facilitar una dirección más activa del debate procesal, acotándolo tan solo a los extremos en que exista discordancia y limitando la prueba al objeto de la discrepancia. La concentración de estos trámites (con sus respectivos traslados de escritos y notificaciones), podrían acortar la duración del procedimiento y reducir el trabajo en la oficina judicial. En lo que hace específicamente a la transacción, su efectiva realización no depende tanto de una nueva redacción del art. 77 LJCA como de cambios normativos en el estatuto de los letrados públicos (como la previsión de ámbitos de transacción sin previa autorización administrativa, o la posibilidad de transacciones confirmables a posteriori). Pero, como se viene diciendo, estas hipotéticas reformas normativas superan con creces los cometidos de esta Sección, por lo que sólo se incluyen en el presente informe como posible indicación para futuras reformas normativas".

Como decimos, para nosotros la mediación intrajudicial en esta jurisdicción se debe residenciar exclusivamente en el ámbito del art. 77 LJCA, llevando a cabo los cambios normativos que sean precisos para potenciarla. Pero no parece ser este el diseño que tiene pensado el CGPJ, como se constata con el documento denominado Guía para la práctica de la mediación intrajudicial ${ }^{7}$, que dedica sus páginas 166 y siguientes a exponer el diseño de la mediación en sede contenciosoadministrativa.

El diseño propuesto parte de definir la mediación como "un medio de solución de litigios alternativo y complementario a la Administración de justicia, en el que dos o más partes legitimadas intentan voluntariamente, en el curso de un proceso contencioso-administrativo, alcanzar por sí mismas un acuerdo, sobre la base de una propuesta elaborada por un tercero mediador". Como puede apreciarse, la nota esencial es la intervención de un tercero a las partes que realiza la función de mediación, lo que obliga a la suspensión del procedimiento. Así se establece en su Base 3.1 que "El comienzo de la mediación suspenderá el proceso judicial si ello fuera necesario. El juez que conozca del procedimiento, si considera que el asunto puede ser susceptible de mediación, dictará una providencia instando a las partes a pronunciarse sobre si aceptan someter su pleito a mediación, para lo cual concederá un término de diez días a fin de que aquéllas muestren su aquies-

\footnotetext{
${ }^{7}$ Consejo General del Poder Judicial, "Guía para la práctica de la mediación intrajudicial”, Separata Revista del Poder Judicial (2013).
} 
cencia, de forma expresa o, en su caso, de forma tácita, cuando no se oponga la Administración demandada".

Es esencial en el diseño pretendido destacar que el mediador lo nombra el Secretario Judicial (Base 3.4) por "el orden que ocupen en el registro oficial de mediadores creado al efecto", en concreto, según la Base 4" "La mediación se realizará por profesionales designados por instituciones de mediación, las entidades públicas o privadas y las corporaciones de derecho público que tengan entre sus fines el impulso de la mediación, facilitando el acceso y organización de la misma, incluida la designación de mediadores". Es decir, la mediación se llevará a cabo por mediadores privados, exactamente lo mismo que ocurre con la mediación regulada en la Ley 5/2012, de 6 de julio, de mediación en asuntos civiles y mercantiles (BOE núm. 162, de 7 de julio, pp. 42924 a 42942).

Así las cosas, resultará que si el juez que conozca del procedimiento considera que el asunto puede ser susceptible de mediación y la Administración no se niega a ello (Base $3^{\mathrm{a}} .1$ ), dictará providencia en la que se contendrán las previsiones contenidas en la Base $3^{\text {a }} .2$, entre ellas, la posibilidad de que las partes "acudan a un primera diligencia informativa" con el mediador o mediadores que se designen así como la necesaria previsión de que sean las partes quienes acudan de manera personal a las sesiones de mediación acompañadas de su asesor legal, así como, "por parte de la Administración, también el técnico en virtud de cuyo informe o actuación se hubiera llegado al acuerdo impugnado", de tal forma que ya nos imaginamos al Abogado del Estado, o al de la Junta de Extremadura por poner un ejemplo cercano, con su carpeta bajo el brazo, acudiendo a una primera sesión informativa, para que un mediador privado, que ni siquiera es necesario que sea técnico en Derecho, le informe sobre las bonanzas de alcanzar un acuerdo que ponga fin a la controversia. En concreto la Base 6.2.3 señala que "En dicha sesión el mediador, con la asistencia del Secretario judicial, informará a las partes de las posibles causas que puedan afectar a su imparcialidad, de las características de la mediación, la organización del procedimiento, las consecuencias jurídicas del acuerdo que se pudiera alcanzar, así como del plazo para firmar el acta de la sesión constitutiva".

Y luego lo imaginamos igualmente acudiendo a la sesión constitutiva del procedimiento mediador, cuya regulación se encuentra en la Base $6^{a} .3$, pactando entre otras cosas "el programa de actuaciones" del proceso negociador, debiendo acudir a él las veces que se pacten.

E igualmente es de imaginar cómo serán las sesiones de mediación, y los argumentos que utilizará el mediador para conseguir que se avenga a un acuerdo amistoso con el ciudadano/a que ponga fin a la controversia.

Y, por último, nos lo imaginamos también abonando la mitad de la minuta del mediador o mediadores, pues es de suponer que, tratándose de mediadores privados, tendrá también que abonar la parte que le corresponda. 
¿Tiene esto algún sentido? A mi juicio ninguno. Y esa es la razón de que actualmente sigamos sin normativa alguna que regule la mediación en nuestra jurisdicción y que no se lleve a cabo la potenciación del único mecanismo de mediación que, a nuestro juicio, es eficaz, rápido y barato, el que permite el artículo 77 LJCA.

\subsection{Nuestra propuesta}

Hemos tenido la oportunidad de dar a conocer nuestra experiencia de mediación intrajudicial, al amparo del artículo 77 LJCA, en la ponencia "Medidas compositivas y alternativas en la jurisdicción contencioso-administrativa", donde demostramos que es posible realizar, como juez, una labor mediadora en esta jurisdicción con resultados constados y constatables. Cerca de 200 han sido los autos aprobando Acuerdos de Transacción Judicial que hemos dictado durante los ochos años que servimos en el Juzgado Contencioso-administrativo núm. 1 de Badajoz, en una experiencia inédita.

Es por ello que no vamos ahora a analizar cuestiones de indudable trascendencia como las materias susceptibles de transacción, remitiendo al lector interesado a ella.

Pero sí queremos recordar lo que significa la existencia del artículo 77 LJCA, cuya potencialidad es extraordinaria. Y lo hacíamos con las siguientes palabras?:

"Cuando la persona a la que afecte la declaración administrativa que supone el acto administrativo impetra el auxilio judicial, por considerar que tal acto no es conforme a Derecho, el interés general al que sirve el acto se ve condimentado (y por ello en cierta forma alterado) por la realidad que supone la formalización del conflicto en sede judicial. Esto es, al análisis de cuál sea el interés general al que sirve un concreto acto administrativo hay que añadir el también interés general de que tal conflicto sea resuelto de la manera más rápida, menos costosa y con la mayor participación del particular interesado.

No nos cabe ninguna duda que forma parte del interés general que los ciudadanos participen de la manera más activa posible en la Administración de Justicia, y no conocemos otra fórmula más contundente para ello que darle la posibilidad de poner fin al conflicto que ha judicializado mediante la fórmula compositiva que supone la transacción judicial.

\footnotetext{
${ }^{8}$ Rojas Pozo, C., "Medidas Compositivas y Alternativas en la jurisdicción contencioso-administrativa", Cuadernos Digitales de Formación, (núm. 12, 2013). Formando parte de la publicación: "Medidas de Agilización de la jurisdicción contencioso-administrativa. Singular tratamiento de la fase de ejecución".

${ }^{9}$ Ídem, p. 3.
} 


\section{Casiano Rojas Pozo}

Y no nos cabe tampoco ninguna duda que forma parte del interés general que el importante coste económico que supone un proceso judicial sea minimizado lo más posible, siendo indudable que la introducción de fórmulas compositivas tiende a conseguirlo.

Es por ello que el legislador ha querido que, pese a la presunción de legalidad y validez de los actos administrativos, cuando un ciudadano toma la decisión (cada vez más difícil, por cierto) de cuestionar en sede judicial su conformidad a Derecho, la Administración haga un nuevo análisis de lo que sea el interés general al que debe servir el concreto acto ya judicializado y, con base a ello, pueda reconsiderar su posición, cediendo en su planteamiento inicial (al igual que el ciudadano), para poner fin al conflicto. De esta forma, "el pacto de autocomposición no sólo no se contrapone al interés público, sino que facilita su satisfacción".

Esta es la finalidad, a mi juicio, del artículo 77 de la Ley 29/1998, de 13 de julio, reguladora de la jurisdicción contencioso-administrativa-BOE de 14 de julio de 1998 (en adelante LJCA), que pretende dar cobertura legal a la imprescindible concesión que la Administración tendrá que hacer para poder transigir, con lo que de esta forma se garantiza el principio de vinculación positiva a la Ley".

Sentado ello, es imprescindible comprender en qué consiste la actuación de los Letrados de la Administración en un proceso negociador para poder diseñar la forma de llevarlo a cabo. A este respecto, y como no parece discutible que la Administración no tiene autonomía de la voluntad para decidir cómo resolver la controversia mediante acuerdo, sino sólo en cuanto con él se consigue mejor satisfacer el interés general en los términos expuestos anteriormente, el análisis que hace en la comparecencia prevista en el artículo 77 LJCA es de pura y simple oportunidad y conveniencia, no de legalidad.

El análisis de oportunidad que realiza el Letrado de la Administración responde a la pregunta de si, a la vista del contenido del acto administrativo impugnado, del expediente y de los argumentos de la demanda y la contestación, estamos ante una cuestión dudosa. $\mathrm{O}$ de otra forma, si la demanda tiene posibilidades de prosperar, y cuál es ese porcentaje. Es evidente que, si el análisis que realiza es que no existe posibilidad alguna, o esta es en un porcentaje muy pequeño, el interés general que por definición representa el acto administrativo conllevará que rechace cualquier posibilidad de alcanzar un acuerdo que ponga fin a la controversia.

Hay que destacar que este análisis de oportunidad lo realiza el órgano que tiene normativamente establecida la defensa de la Administración (Abogacía del Estado, Servicios Jurídicos de la respectiva Comunidad Autónoma, Letrado del respectivo Ayuntamiento etc.), es decir, casi con toda seguridad un órgano distinto del que adoptó el acto administrativo cuestionado, lo que facilitará un 
análisis más imparcial. Y a este respecto debemos decir que nos parece totalmente contraproducente que al acto de negociación acuda el técnico funcionario cuyo informe sustentó el acto impugnado, como se propugna en el diseño realizado por el CGPJ, pues difícilmente podrá alcanzarse con su presencia, al mantenerse él en una postura de estricta legalidad, que no es, como decimos, el análisis que hay que hacer, sino de oportunidad.

Y si el resultado de ese análisis es que hay un margen razonable, en términos cuantitativos, para que el recurso pueda prosperar, entrará entonces a analizar la conveniencia del acuerdo que se le propone; esto es, el Letrado de la Administración verificará si la rebaja en su pretensión inicial que inexorablemente debe hacer el ciudadano/a para alcanzar el acuerdo, compensa ser aceptada en términos de interés general, entrando entonces en negociación para alcanzar el equilibrio entre oportunidad y conveniencia.

Así las cosas, se comprende que la intervención que tiene que hacer el juez en la función mediadora que le otorga el artículo 77 LJCA no es en búsqueda de la "legalidad" (que le convertiría en juez y parte), sino de búsqueda de la "oportunidad", como presupuesto imprescindible para que la Administración pueda transar o llegar a acuerdos, y luego de búsqueda de "conveniencia" para ambas partes, teniendo siempre en cuenta el interés general en la forma definida anteriormente cuando el conflicto está ya residencia en sede jurisdiccional.

Es por ello que, desde nuestro punto de vista, carece de sentido la imputación de pérdida de imparcialidad que se sostiene por muchos como una de las objeciones para potenciar el artículo 77 LJCA. El juez en esa comparecencia no lleva toga.

Otra de las objeciones que tradicionalmente se hacen a la mediación intrajudicial del artículo 77 LJCA consiste en la pérdida de confidencialidad. Se argumenta $^{10}$ que "la mediación que actualmente se está desarrollando por los jueces y magistrados de este orden jurisdiccional se realiza por el propio juez. Es decir, no se trata de un tercero imparcial que auxilia a las partes en la resolución de un conflicto del que es ajeno, sino el juez que está conociendo del asunto. Esto supone unas limitaciones significativas. Principalmente, la participación del juez vicia en parte el proceso de mediación dado que, si el acuerdo no se alcanza, éste habrá tenido acceso a información que puede que las partes no hubiesen revelado en el marco del proceso. Esto quiebra uno de los principios que informan toda mediación, la confidencialidad y puede hacer perder interés en su utilización".

Esta objeción se salva con total facilidad si tenemos en cuenta que se trata de una "comparecencia" en el seno de un procedimiento judicial, y, por tanto, sometida al régimen de documentación previsto con carácter general en el Ar-

${ }^{10}$ Belando Garín, B., "La mediación administrativa: una realidad jurídica” en López Ramón, F. (coord.), Las prestaciones patrimoniales públicas no tributarias y la resolución extrajudicial de conflictos, INAP, Madrid, 2015, pp. 265-273. Obtenido en www.mediacion.icav.es 
tículo 147.1 de la Ley de Enjuiciamiento Civil, de 7 de enero (BOE núm. 7 de 08/01/2000) (Documentación de las actuaciones mediante sistemas de grabación y reproducción de la imagen y el sonido), a cuyo tenor "Las actuaciones orales en vistas, audiencias y comparecencias celebradas ante los jueces o magistrados o, en su caso, ante los secretarios judiciales, se registrarán en soporte apto para la grabación y reproducción del sonido y la imagen y no podrán transcribirse”. De esta forma, deberá quedar constancia gravada, por manifestación expresa del juez al inicio de la comparecencia, que nada de lo dicho en la misma podrá ser tenido en consideración a la hora de resolver el litigio en el caso de que el Acuerdo no se consiga. Y de esta forma la parte afectada podrá hacer valer el compromiso de confidencialidad en el caso de ser vulnerado.

Y en el mismo sentido de impedir vulneraciones de confidencialidad, hay que recordar que el artículo 77 LJCA fija la realización de la comparecencia "una vez formuladas demanda y contestación", con lo que, al menos en el procedimiento ordinario, no existe riesgo alguno de aprovechar lo manifestado en la comparecencia para llegar a un acuerdo, pues el debate, tanto en cuanto a alegaciones como a medios de prueba, está totalmente cerrado. Y en el procedimiento abreviado no podemos tampoco olvidar que no se pueden trasvasar a esta jurisdicción planteamientos que quizás pudieran tener sentido en otras (especialmente la civil), pues aquí nos encontramos, esencialmente, con una jurisdicción revisora en la que ya existe un expediente administrativo donde, en circunstancias normales, las partes han plasmado ya su posicionamiento.

Otro conjunto de objeciones que se realizan con frecuencia es el que se plasma en la STS de 11 de diciembre de 1996 (RJ 1969, 5689), cuando en su último considerando razona que "no cabe la posibilidad de transacciones efectuadas por los entes públicos en materia jurídico-administrativa, como es la aquí debatida, dada la indisponibilidad que sobre los actos administrativos se produce por parte de la Administración que los ha emanado, en cuanto que tales actos van dirigidos a satisfacer el interés público, habida cuenta asimismo de la irrevocabilidad de las situaciones jurídicas establecidas por tales actos administrativos y, sobre todo, por la presunción de legitimidad que acompaña a los actos administrativos (...) y que quedaría destruida por la posibilidad de efectuar cesiones o concesiones recíprocas sobre los derechos o situaciones jurídicas contenidas en tales actos, es decir, que la presunción de legalidad está en pugna con lo que es sustancia de la transacción, cual la incertidumbre respecto de la validez o invalidez en Derecho de una determinada actuación o conducta con efectos jurídicos".

Frente a ello cabe decir que el ordenamiento jurídico ya prevé alguna forma de "disposición sobre los actos administrativos", como es el supuesto de la revocación de los actos de gravamen o desfavorables para los ciudadanos, previsto en el artículo 105.1 de la Ley 30/92, que "no se configura como un directo cauce impugnatorio por defectos de legalidad, sino como una facultad de dejar sin efecto 
actos administrativos por decisiones de contrario imperio" (STSJ de Extremadura de 25/03/2010, rec. 650/2008, ROJ 503/2010), siendo unánimemente reconocida como una potestad discrecional (STSJ del País Vasco de 15/05/2012, rec. 736/2010, ROJ 1419/2012), por señalar alguna, habiéndose llegado a indicar que "la revocación de una sanción no es en sí mismo ilegal" (STSJ de Andalucía de 28/05/2012, rec. 435/2010, ROJ 5326/2012).

Y otra excepción al principio de indisponibilidad de los actos y la irrevocabilidad de las situaciones la constituye precisamente el artículo 77 de la LJCA, que no hace sino trasponer, a sede de recurso contencioso-administrativo, la facultad expresa y general contenida en el artículo 1812 del Código Civil (Real Decreto de 24 de julio de 1889 por el que se publica- BOE núm. 206 de 25/07/1889) y la implícita contenida en el artículo 25 del Real Decreto Legislativo 3/2011, de 14 de noviembre, que aprueba el Texto Refundido de la Ley de Contratos del Sector Público (BOE núm. 276, de 16/11/2011).

Pero, es más, a nuestro juicio la previsión legal contenida en el artículo 77 de la LJCA debe ser considerada como norma especial sobre la presunción de legalidad contenida en el artículo 57.1 de la Ley 30/92, puesto que parte, como presupuesto de normalidad, de la existencia del acto administrativo. Esto es, la Ley quiere que, cuando un ciudadano asume la carga que supone impugnar en sede jurisdiccional su validez, la Administración pueda (cumpliendo los requisitos formales que establece) ceder en su posición inicial a fin de poner término al pleito, lo que puede conllevar el dejar sin efecto el acto administrativo cuestionado, con base en el análisis de oportunidad y conveniencia que hemos visto, y en la consideración de que con ello se va a conseguir salvaguardar mejor el interés general.

En parecidos términos se pronuncia Bustillo Bolado cuando escribe que "11 "no creo que las recíprocas concesiones que acompañan la transacción supongan una lesión para la presunción de legitimidad del acto administrativo. Parece más bien que ambas instituciones se mueven en planos diferentes. Una cosa es la presunción de validez de los actos administrativos (art. 57.1 de la Ley 30/92) cuya consecuencia inmediata es la carga del recurso para el sujeto perjudicado; y otra cosa bien distinta es que ante un acto administrativo, o ante su presumible dictado, surja una razonable controversia jurídica que ante la expectativa de un más o menos largo proceso judicial de resultado incierto, a la vista del interés público y al amparo de la Ley, aconsejen a la Administración una rápida y eficaz solución por medio de recíprocas concesiones".

Otro de los argumentos esgrimidos por los partidarios de la postura negativa a la transacción en Derecho Administrativo es descrito por Jesús González Pérez

\footnotetext{
${ }^{11}$ Bustillo Bolado, R. O., Convenios y Contratos Administrativos: Transacción, Arbitrajes y Terminación Convencional del Procedimiento, Thomson Reuters Aranzadi, Pamplona, 2010, p. 348.
} 


\section{Casiano Rojas Pozo}

escribiendo que "la Administración puede llegar a la conclusión de que el acto impugnado en un proceso administrativo es válido o inválido, y en ambos casos, de adoptarse el acuerdo de transigir, resultaría viciado: en el primer caso, porque si el acto es válido la conclusión de transigir vendrá determinada por el temor del éxito en el proceso o por la intención de favorecer al demandante; en el segundo, porque su voluntad estaría dirigida a aprovecharse de la duda, del temor o de la necesidad de la parte contraria".

Este argumento, puramente teórico, pues como escribimos en la ponencia citada anteriormente, no tiene en cuenta la realidad, que es que "el número de sentencias estimatorias ronda entre el $45 \%$ de las demandas formuladas y el de desestimatorias en un $55 \%$. Dicho resultado puede tener diferentes lecturas. Así podría afirmarse que la Administración se equivoca en un $45 \%$ de los recursos formulados o que los ciudadanos yerran en su decisión de acudir a los órganos o tribunales contenciosos en un $55 \%$ \%. Es decir, existe una tercera posibilidad que escapa a la objeción: que la Administración tenga dudas razonables sobre la validez o nulidad del acto (zona de grises). En tal caso utilizar el mecanismo legalmente previsto en los artículos 1809 y 1812 del Código Civil y 77 LJCA no implica vulnerar el deber de actuar con objetividad y, además, la transacción en estos casos supone un instrumento garantizador del interés general, tal y como lo estamos conceptuando cuando el conflicto está judicializado.

Hemos oído también en alguna ocasión, que la utilización de la fórmula de mediación que permite el artículo 77 LJCA supone una actuación que en cierta forma violenta o intimida a los letrados, tanto de la parte como de la Administración, que, de facto, se ven compelidos a someterse al proceso mediador, aunque no estén de acuerdo con él.

Pues bien, este planteamiento carece de sentido alguno, pues es evidente el proceso mediador es absolutamente voluntario como no puede ser de otra manera.

Pero es que, además, la experiencia demuestra todo lo contrario. Para el ciudadano/a, tener la oportunidad de estar personalmente en el despacho del juez, siendo protagonista en primera persona de un proceso negociador que puede culminar con la estimación de una parte de sus pretensiones, cuando viene de someterse a un expediente administrativo en el que no le han dado la razón, supone ya una victoria y, desde luego, una muestra evidente de buena administración de justicia, pues tal vez haya que recordar de nuevo que Administrar Justicia es mucho más que dictar sentencia. Por lo mismo la Guía ${ }^{13}$, señala como uno de los objetivos de la mediación: "Trabajar en la transformación de la relación Administración/ciudadano, a través de la búsqueda de fórmulas flexibles que permitan que

\footnotetext{
${ }^{12}$ González Pérez, J., Manual de Derecho Procesal, 2. ${ }^{\text {a }}$ ed., Civitas, Madrid, 1992, pp. 374-375.

13 "Guía para la práctica de la mediación intrajudicial”, cit.
} 
la potestad administrativa se pueda también ejercer aprovechando la comunicación entre las partes y la introducción por ellas de aspectos subjetivos que suelen quedar al margen del procedimiento formal".

Rechazadas las objeciones que sirven de excusa para no potenciar la mediación intrajudicial por el juez, no parecen necesarias muchas líneas para destacar las ventajas que conlleva. Es una mediación rápida, pues no supone la paralización del procedimiento. Es una mediación eficaz, pues su planteamiento supone, a priori, la consideración de que se trata de materia transable y que existe cierto margen a la negociación (materia dudosa). Y es una mediación gratuita para el ciudadano/a. Además de ello, y no es baladí, es la forma más contundente que encontramos para hacer partícipe a la ciudadanía en la Administración de Justicia.

\section{CONCLUSIONES}

A nuestro juicio, la falta de desarrollo de la mediación administrativa tiene su origen en la falta de conciencia mediadora de la sociedad española. Para cambiar esta situación es preciso que nuestros hijos conformen su personalidad sabiendo que los problemas se pueden solucionar por una vía distinta a la pura fuerza bruta y a la vía judicial. La introducción en las escuelas de los programas "Educando en Justicia y Mediación" es imprescindible.

Debe potenciarse la vía de la mediación en sede administrativa, mediante la creación de Entes Administrativos de Mediación.

Una vez judicializado el conflicto, la única mediación rápida, eficaz y barata es la mediación realizada por el juez del proceso en el seno del artículo 77 LJCA. La derivación a la mediación por terceros mediadores privados está llamada al fracaso más absoluto.

\section{BIBLIOGRAFÍA}

BELANDO GARÍN, B., "La mediación administrativa: una realidad jurídica" en López Ramón, F. (coord.), Las prestaciones patrimoniales públicas no tributarias y la resolución extrajudicial de conflictos, INAP, Madrid, 2015, pp. 265-273.

BUSTILLO BOLADO, R. O., Convenios y Contratos Administrativos: Transacción, Arbitrajes y Terminación Convencional del Procedimiento, Thomson Reuters Aranzadi, Pamplona, 2010

COMISIÓN GENERAL DE CODIFICACIÓN, Informe explicativo y propuesta de anteproyecto de ley de eficiencia de la Jurisdicción Contencioso-Administrativa, Ministerio de Justicia, Madrid, 2013. 
COMISIÓN GENERAL DE CODIFICACIÓN, Propuesta de anteproyecto de Ley de eficiencia de la Jurisdicción Contencioso-administrativo, Ministerio de Justicia, Madrid, 2013.

CONSEJO GENERAL DEL PODER JUDICIAL, "Guía para la práctica de la mediación intrajudicial”, Separata Revista del Poder Judicial (2013).

GONZÁLEZ PÉREZ, J., Manual de Derecho Procesal, 2. ${ }^{a}$ ed., Civitas, Madrid, 1992.

ROJAS POZO, C., "Medidas Compositivas y Alternativas en la jurisdicción contencioso-administrativa", Cuadernos Digitales de Formación, (núm. 12, 2013). 